\title{
Effects of Silica Loading on the Absorption of Carbon Dioxide by Mixed Matrix Membranes
}

\author{
Abdul Latif Ahmad, ${ }^{*}$ Aishah Rosli, Siew Chun Low and Jit Kang Lim \\ School of Chemical Engineering, Universiti Sains Malaysia, Engineering Campus, \\ 14300 Nibong Tebal, Pulau Pinang, Malaysia \\ ${ }^{*}$ Corresponding author: chlatif@usm.my
}

Published online: 25 February 2018

To cite this article: Ahmad, A. L. et al. (2018). Effects of silica loading on the absorption of carbon dioxide by mixed matrix membranes. J. Phys. Sci., 29(Supp. 1), 91-97, https://doi.org/10.21315/jps2018.29.s1.12

To link to this article: https://doi.org/10.21315/jps2018.29.s1.12

\begin{abstract}
Fumed silica nanoparticles, TS-530 were used with polyvinylidene fluoride (PVDF) in this work to produce mixed matrix membranes (MMM). Various nanoparticle loading were used to observe the effects of different nanoparticle loading on the characteristics, morphology and gas absorption performance of the resulting MMMs. $0.5 \mathrm{wt} \%, 1.0 \mathrm{wt} \%, 1.5 \mathrm{wt} \%, 3 \mathrm{wt} \%, 5 \mathrm{wt} \%$ and $10 \mathrm{wt} \%$ silica nanoparticles were added into the polymer dope solution before the membranes were cast in flat sheet configuration. Membrane contact angle tests showed an increase of the contact angle with silica loading, which is a desired characteristic in membrane gas absorption process. Energy dispersive $X$-ray (EDX) surface mapping of these MMMs indicated that the nanoparticles were quite well distributed in the polymer matrix despite its tendency to agglomerate. Permeability of carbon dioxide $\left(\mathrm{CO}_{2}\right)$ in a gas mixture of $\mathrm{CO}_{2}$ and nitrogen $\left(\mathrm{N}_{2}\right)$ for MMMs were better compared to the pure PVDF membrane, with $1 \mathrm{wt} \%$ silica loading having the best $\mathrm{CO}_{2}$ permeability. Selectivity, however, decreased with increasing nanoparticles loading, which may be the result of poor compatibility between the nanoparticles and the polymer matrix.
\end{abstract}

Keywords: Mixed matrix membrane, $\mathrm{CO}_{2}$ absorption, membrane gas absorption, silica loading, polyvinylidene

\section{INTRODUCTION}

A method proposed to reduce the emission of greenhouse gases is carbon capture and storage (CCS) system. Membrane gas absorption (MGA) is an attractive alternative to the conventional chemical absorption systems. Of the commonly used hydrophobic polymers, polyvinylidene fluoride (PVDF) is the most attractive 
due to its processability. ${ }^{1}$ Mixed matrix membranes (MMMs) have the potential to show better performance by combining the desired characteristics of polymer and inorganic membranes. ${ }^{2}$ Research has found that MMMs incorporating nonporous inorganic particles do not perform as predicted by the Maxwell model, which assumed decreased gas permeabilities in MMM compared to pure polymeric membranes. ${ }^{3}$ The increase in free volume from the addition of non-porous silica nanoparticles causes an increase of gas permeability with silica content; however, the selectivity can decrease. ${ }^{3,4}$ However, the incorporation of fumed silica nanoparticles in glassy polymers enhanced the gas and vapour permeability as well as the reverse selectivity for condensable $\mathrm{C} 3+$ hydrocarbons over smaller gases. ${ }^{5}$ In the present study, silica nanoparticles at different loadings were added into PVDF, and the effects on the characteristics and performance of the resulting MMMs were investigated. The performance of the MMM in a MGA process to absorb $\mathrm{CO}_{2}$ from flue gas were observed and compared with the pure PVDF membrane.

\section{EXPERIMENTAL}

\subsection{Materials}

PVDF from Solef Company (Solef 6010/1001) was used as the polymer to synthesise the membranes. N-Methyl-2-pyrrolidone (NMP) from Sigma-Aldrich was used as a solvent. Hydrophobic fumed silica nanoparticles, Cabosil TS530 containing trimethylsilyl groups was kindly supplied by Cabot Corporation (Tuscola, IL, United States).

\subsection{Membrane Preparation}

To synthesise MMMs, the desired amount of fumed silica nanoparticles were added into the solvent and stirred for $30 \mathrm{~min}$. A range of nanoparticle loading of $0.5 \mathrm{wt} \%$ to $10 \mathrm{wt} \%$ was chosen as the addition of inorganic fillers beyond this amount would cause the particles to agglomerate too much. The mixture was then sonicated for $30 \mathrm{~min}$ to ensure that the nanoparticles were well dispersed within the solution. The PVDF powder was slowly added and then stirred continuously at $60^{\circ} \mathrm{C}$ for $24 \mathrm{~h}$. The pure PVDF membrane was prepared in a similar manner, without the addition of the silica nanoparticles. The dope polymer solutions were cast by a casting machine (Elcometer 4340, United Kingdom) on a glass plate using a casting blade to set a thickness gap of $400 \mu \mathrm{m}$. The cast polymer solution was immediately immersed into a coagulation bath containing $20 \mathrm{wt} \%$ ethanol in water for $24 \mathrm{~h}$. Then, the membrane film was thoroughly washed with water to remove the excess chemicals. 


\subsection{Characterisation}

The water contact angle of the MMMs was measured using a goniometer (RaméHart Instruments Co.). The pore size distribution of the membranes was obtained by wetting the membrane samples with Porefil for $10 \mathrm{~min}$ before using a porometer, Porolux 1000 (Beneflux Scientific, Belgium) with $\mathrm{N}_{2}$ gas. The thermal degradation of membranes was observed in inert $\mathrm{N}_{2}$ through a thermal gravimetric analysis (TGA). The liquid entry pressure of the membranes $\left(\mathrm{LEP}_{\mathrm{w}}\right)$ was measured by a porometer using the bubble point method. ${ }^{6}$ The morphology of the membranes was observed using field emission scanning electron microscope (FESEM, SUPRA TM $35 \mathrm{vp}$ Zeiss, Germany). EDX surface mapping for the top surface of the MMMs was done to observe the dispersion of silica nanoparticles on the surface of the MMMs.

\subsection{Gas Absorption Test}

Membrane sample with a diameter of $19 \mathrm{~mm}$ was placed in the membrane module. Pure $\mathrm{CO}_{2}$ and $\mathrm{N}_{2}$ gases at $100 \mathrm{ml} \mathrm{min}{ }^{-1}$ were used as feed gas while distilled water at $100 \mathrm{ml} \mathrm{min}{ }^{-1}$ was used as the liquid absorbent in the MGA system. The liquid absorbent from the outlet was collected to measure the absorbed $\mathrm{CO}_{2}$ from the gas stream using chemical titration method. ${ }^{7}$ The $\mathrm{CO}_{2}$ flux through the membrane can be determined using Equation 1:1

$$
\mathrm{CO}_{2_{f l u x}}=\frac{C_{\mathrm{CO}_{2}} \times Q_{a b s o r b e n t}}{A}
$$

where $\mathrm{C}_{\mathrm{CO}_{2}}$ is the concentration of absorbed $\mathrm{CO}_{2}, Q_{\text {absorbent }}$ is the absorbent flow rate $(1 / \mathrm{s})$ and $A$ is the effective membrane surface area $\left(\mathrm{m}^{2}\right)$.

\section{RESULTS AND DISCUSSION}

\subsection{Membrane Characterisation}

In MGA process, it is desirable for the membrane to be hydrophobic to avoid membrane wetting, which causes the membrane performance to deteriorate. The characterisation results of synthesised membranes are shown in Table 1. The addition of the hydrophobic silica nanoparticles to the already hydrophobic PVDF polymer initially showed a decrease in water contact angle. However, with the addition of more silica nanoparticles, the water contact angle of the MMMs showed a steady increase, which could increase the membrane sustainability in 
the long run. $\mathrm{LEP}_{\mathrm{w}}$ depends on the wettability, connectivity and surface pore size of the membrane. ${ }^{6}$ The increasing $\mathrm{LEP}_{\mathrm{w}}$ of the MMMs with silica loading was related to the presence of the hydrophobic modified silica nanoparticles. From the TGA analysis, it was found that the pure PVDF membrane began to lose weight at approximately $188^{\circ} \mathrm{C}$, but the presence of silica nanoparticles increased this value. The temperatures at 1\% $\left(\mathrm{T}_{1}\right)$ and 5\% $\left(\mathrm{T}_{5}\right)$ weight loss increased with silica loading, proving that the addition of fumed silica nanoparticles enhanced the thermal stability of the MMMs. ${ }^{8}$

Table 1: Characterisation results of synthesised membranes.

\begin{tabular}{lcccc}
\hline Membrane & Pore size $(\mu \mathrm{m})$ & LEPw $($ bar $)$ & Porosity $(\%)$ & Contact angle $\left({ }^{\circ}\right)$ \\
\hline Pure PVDF & 0.12 & 4.747 & 76.77 & 90.7 \\
$0.5 \%$ TS-530 & 0.10 & 7.424 & 75.86 & 84.3 \\
$1 \%$ TS-530 & 0.08 & 7.511 & 77.57 & 91.4 \\
$1.5 \%$ TS-530 & 0.09 & 7.567 & 78.50 & 95.6 \\
$3 \%$ TS-530 & 0.09 & 7.618 & 77.46 & 99.1 \\
$5 \%$ TS-530 & 0.10 & 7.841 & 72.70 & 108.5 \\
$10 \%$ TS-530 & 0.11 & 7.870 & 66.51 & 110.7 \\
\hline
\end{tabular}

Figure 1 shows the morphology of the pure PVDF membrane and MMMs obtained from the FESEM analysis. The morphologies of the membranes were similar, but MMMs with $3 \mathrm{wt} \%, 5 \mathrm{wt} \%$ and $10 \mathrm{wt} \%$ particles loading had visibly denser sponge-like bottom layers, and this was further confirmed by the porosity of the membranes, which decreased after the $1.5 \mathrm{wt} \%$ silica loading. MMMs had lower thickness compared to the pure membrane due to the alteration of PVDF chain packing with addition of nanoparticles. The EDX results show that the fumed silica nanoparticles were well-distributed on the surface of the MMMs. This is attributed to the hydrophobic nature of the modified silica nanoparticles. The average pore radius of the MMMs decreased when $1 \mathrm{wt} \%$ silica was used, then increased with silica loading. The large pore sizes of the pure PVDF membrane can be attributed to the large finger-like layer. In the phase-inversion process, the thermodynamic and kinetic effects determined the structure of the membrane. Contrary to the effects of addition of PEG-400 in the dope solution by Mansourizadeh and Pouranfard, the addition of fumed silica nanoparticles into the dope solution had possibly increased the thermodynamic miscibility of the solution, which discouraged liquid-liquid phase separation and formed membranes with lower porosity. ${ }^{9}$ Furthermore, the addition of inorganic fillers increased dope solution viscosity, delaying the diffusion during the phase separation. This delay could suppress the growth of the finger-like layer, producing membranes with lower pore volume smaller finger-likes. 
(a) Pure PVDF membrane

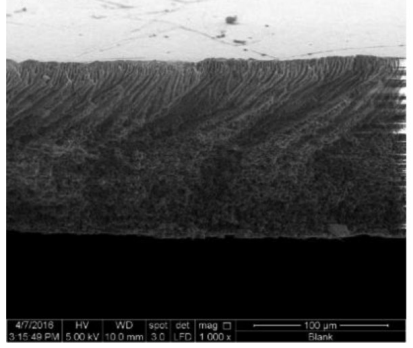

(b) $1 \%$ TS-530

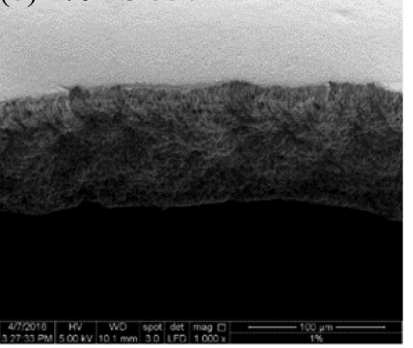

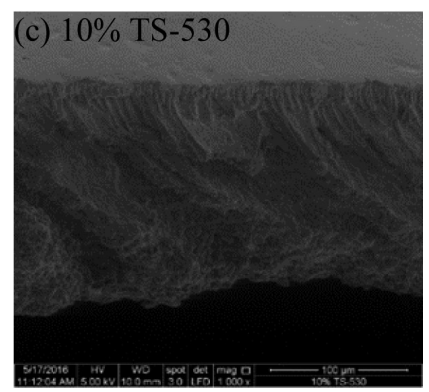

Figure 1: FESEM images of the cross-sectional view of (a) pure PVDF membrane and MMMs containing (b) 1\% and (c) 10\% TS-530 fumed silica nanoparticles.

\subsection{Membrane Absorption Test}

Figure 2 shows the $\mathrm{CO}_{2}$ absorption flux and $\mathrm{CO}_{2} / \mathrm{N}_{2}$ selectivity of the synthesised MMMs. The highest absorption flux achieved by the synthesised MMMs was at $1.5 \mathrm{wt} \%$ silica loading with $2.82 \times 10^{-4} \mathrm{~mol} \mathrm{~m}^{-2} \mathrm{~s}^{-1}$ while the highest $\mathrm{CO}_{2} / \mathrm{N}_{2}$ selectivity was at $1 \mathrm{wt} \%$ silica loading with 22.5 . Comparing these $\mathrm{CO}_{2}$ fluxes and selectivity with the ones obtained by the pure PVDF membrane $\left(2.84 \times 10^{-4}\right.$ mol m $\mathrm{m}^{-2} \mathrm{~s}^{-1}$ and 7.18, respectively), it can be seen that while the MMMs did not manage to surpass the pure PVDF membrane in terms of $\mathrm{CO}_{2}$ flux, its selectivity increased significantly. The large pore size of the pure PVDF membrane was the reason for the high $\mathrm{CO}_{2}$ and $\mathrm{N}_{2}$ flux, causing its selectivity to decrease. On the other hand, $1 \mathrm{wt} \%$ MMM had smaller pore size which accounted for the significant increase in selectivity, but the narrow gaps between silica-polymer interface allowed the $\mathrm{CO}_{2}$ to diffuse through the membrane. Higher silica loadings led to larger agglomeration

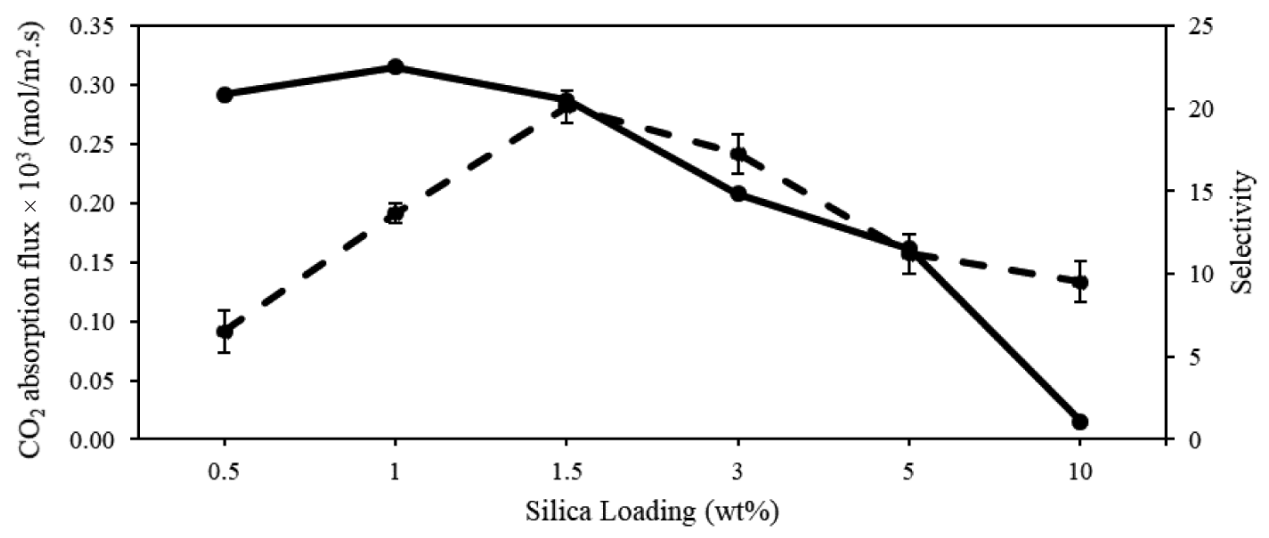

—•Flux $(\mathrm{mol} / \mathrm{m} 2 . \mathrm{s}) \times 10^{\wedge} 3 \longrightarrow$ Selectivity

Figure 2: $\mathrm{CO}_{2}$ flux and selectivity of MMMs with silica loading. 
of the inorganic fillers, forming more non-selective voids, which was why the $\mathrm{CO}_{2} / \mathrm{N}_{2}$ selectivity decreased. ${ }^{10}$ The decrease in $\mathrm{CO}_{2}$ permeability with higher silica loading can be attributed to the decrease in porosity of the MMMs, as well as the significant change in the polymer chain packing, causing the gas diffusion path to become longer and more tortuous. ${ }^{1}$

\section{CONCLUSION}

Hydrophobic PVDF mixed matrix membranes incorporated with non-porous fumed silica nanoparticles were synthesised in this work. The presence of these hydrophobic nanoparticles gave rise to the water contact angle and liquid entry pressure of the MMMs, while decreasing their porosity. The increase in inorganic fillers reduced the depth of finger-like layer of the MMMs and caused the spongelike layer to become more dense, even as the average surface pore size to increase as a result of the formation of large silica aggregates. In the gas absorption test using an MGA system, the MMM containing 1.5\% silica loading had the highest $\mathrm{CO}_{2}$ absorption flux among the MMMs while the MMM with $1 \%$ silica loading had the highest $\mathrm{CO}_{2} / \mathrm{N}_{2}$ selectivity which is almost three times the selectivity of the pure PVDF membrane.

\section{ACKNOWLEDGEMENTS}

The authors acknowledge the research grant provided by the Universiti Sains Malaysia under the Exploratory Research Grant Scheme (Project no.: 6730110) and the Fundamental Research Grant Scheme (Project no.: 6071334).

\section{REFERENCES}

1. Ahmad, N. A. et al. (2017). $\mathrm{CO}_{2}$ Removal using membrane gas absorption with PVDF membrane incorporated with POSS and SAPO-34 zeolite. Chem. Eng. Res. Des., 118, 238-247, https://doi.org/10.1016/j.cherd.2016.12.019.

2. Ahmad, A. L. et al. (2012). Prospect of mixed matrix membrane towards $\mathrm{CO}_{2}$ separation. J. Membr. Sci. Technol., 2(3), 1-2, https://doi.org/10.4172/2155$9589.1000 \mathrm{e} 110$.

3. Ahn, J. et al. (2008). Polysulfone/silica nanoparticle mixed-matrix membranes for gas separation. J. Membr. Sci., 314, 123-133, https://doi. org/10.1016/j.memsci.2008.01.031. 
4. Takahashi, S. \& Paul, D. R. (2006). Gas permeation in poly(ether imide) nanocomposite membranes based on surface-treated silica. Part 1: Without chemical coupling to matrix. Polym., 47(21), 7519-7534, https://doi.org/ 10.1016/j.polymer.2006.08.029.

5. Merkel, T. C. (2003). Sorption, transport, and structural evidence for enhanced free volume in poly(4-methyl-2-pentyne)/fumed silica nanocomposite membranes. Chem. Mater., 15, 109-123, https://doi.org/10.1021/cm020672j.

6. Ooi, B. S. et al. (2012). Preparation of polyvinylidene fluoride membrane via dual coagulation bath system and its wettability study. J. Appl. Polym. Sci., 124, 225-232, https://doi.org/10.1002/app.36269.

7. Korminouri, F. et al. (2015). Surface modification of polysulfone hollow fiber membrane spun under different air-gap lengths for carbon dioxide absorption in membrane contactor system. Chem. Eng. J., 264, 453-461, https://doi.org/10.1016/j.cej.2014.11.110.

8. Ahn, J. et al. (2010). Gas transport behavior of mixed-matrix membranes composed of silica nanoparticles in a polymer of intrinsic microporosity (PIM-1). J. Membr. Sci., 346, 280-287, https://doi.org/10.1016/j.memsci. 2009.09.047.

9. Mansourizadeh, A. \& Pouranfard, A. R. (2014). Microporous polyvinylidene flouride hollow fiber membrane contactors for $\mathrm{CO}_{2}$ stripping: Effect of PEG-400 in spinning dope. Chem. Eng. Res. Des., 92, 181-190, https://doi. org/10.1016/j.cherd.2013.06.028.

10. Goh, P. S. et al. (2011). Recent advances of inorganic fillers in mixed matrix membrane for gas separation. Sep. Purif. Technol., 81, 243-264, https://doi. org/10.1016/j.seppur.2011.07.042. 